\title{
Catechol O-Methyltransferase (COMT) mRNA Expression in the Dorsolateral Prefrontal Cortex of Patients with Schizophrenia
}

\author{
Mitsuyuki Matsumoto*,', Cynthia Shannon Weickert', Senda Beltaifa', Bhaskar Kolachana', Jingshan Chen', \\ Thomas M Hyde', Mary M Herman', Daniel R Weinberger', Joel E Kleinman' \\ 'Clinical Brain Disorders Branch, Intramural Research Program, National Institute of Mental Health, Bethesda, MD, USA
}

\begin{abstract}
Human prefrontal cortical neurons express catechol O-methyltransferase (COMT), an enzyme that inactivates the neurotransmitter dopamine. A functional polymorphism of COMT, $\mathrm{Val}{ }^{108 / 158} \mathrm{Met}$, affects prefrontal function, and the high-activity $\mathrm{Val}$ allele has been reported to be a genetic risk factor for schizophrenia. We used in situ hybridization histochemistry to measure mRNA levels of COMT in the dorsolateral prefrontal cortex (DLPFC) of patients with schizophrenia $(N=14)$ and of normal controls $(N=15)$. While the groups did not differ in terms of mean level of COMT mRNA, there was a significantly different laminar pattern of COMT mRNA expression in pyramidal neurons $(F=2.68, \mathrm{df}=4,108, P<0.04)$; patients with schizophrenia had relatively lower levels in the superficial (II/III) layers and higher levels in the intermediate/deep (IV/V) layers $(P<0.0 \mathrm{I})$, while in controls, the expression was homogeneous across layers. Neither the mean level nor the laminar distribution of COMT mRNA was related to the $\mathrm{Val}{ }^{108 / 158}$ Met genotype, suggesting that the feedback regulation of mRNA level is not a compensation for the functional effect of the COMT polymorphism. The disease-related laminar difference of COMT expression may be involved in dysregulation of dopamine signaling circuits in the DLPFC of patients with schizophrenia.

Neuropsychopharmacology (2003) 28, I52 I-1530, advance online publication, I I June 2003; doi: I0.1038/sj.npp. 13002 I 8
\end{abstract}

Keywords: cortical layer; DLPFC; dopamine; functional Val/Met polymorphism; human brain; in situ hybridization histochemistry; pyramidal neuron

\section{INTRODUCTION}

Catechol $O$-methyltransferase (COMT) catalyzes the transfer of a methyl group from $S$-adenosyl-L-methionine to dopamine, generating 3-methoxytyramine, which is one of the mechanisms for inactivating dopamine after it is secreted (Lundstrom et al, 1995; Mannisto and Kaakkola, 1999). Previous experimental data indicate that COMT is especially relevant in modulating prefrontal cortical dopamine neurotransmission. First, studies of COMT knockout mice have demonstrated that dopamine levels are increased in the prefrontal cortex of these mice under varying conditions, but not in the striatum (Gogos et al, 1998; Huotari et al, 2002). Pharmacological studies in rats have also shown that the catabolic flux of synaptic dopamine through the COMT pathway is much greater in the

\footnotetext{
*Correspondence: Dr M Matsumoto, Present address: Genomics Research, Yamanouchi Pharmaceutical Co., Ltd., 21 Miyukigaoka, Tsukuba, Ibaraki 305-8585, Japan, Tel: + 8I-298-52-5। II, Fax: + 8I298-52-5444, E-mail: matsum_m@yamanouchi.co.jp

Received 02 January 2003; revised 13 March 2003; accepted 14 April 2003

Online publication: 23 April 2003 at http://www.acnp.org/citations/ Npp0423002/default.pdf
}

prefrontal cortex as compared to the striatum (Karoum et al, 1994). Our group has recently demonstrated that COMT mRNA is expressed primarily in neurons in the prefrontal cortex in both rodents and humans, correcting earlier assumptions that COMT was a non-neuronal enzyme in the brain. We have also found that COMT mRNA levels in the prefrontal cortex are significantly higher than in the striatum in both species (Matsumoto et al, 2003). The relatively high levels of COMT and the low levels of dopamine transporters at synapses in the prefrontal cortex probably contribute to the relative functional specificity for COMT to prefrontal dopamine metabolism, in comparison to the striatum, where neuronal uptake by abundant dopamine transporters terminates the synaptic action of dopamine (Garris et al, 1993; Giros et al, 1996; Lewis et al, 2001; Mazei et al, 2002; Sesack et al, 1998; Wayment et al, 2001). Finally, we and other groups have demonstrated that a functional polymorphism of the COMT gene, a valine to methionine substitution at codon 108/158 generating a three- to fourfold less active COMT enzyme (Lachman et al, 1996; Lotta et al, 1995), affects dopamine-related prefrontal cortical function in humans (Bilder et al, 2002; Egan et al, 2001; Goldberg et al, in press; Joober et al, 2002; Malhotra et al, 2002; Mattay et al, 2003; Rosa et al, 2002). 
Deficits in prefrontal-related executive cognition and working memory are prominent components of cognitive dysfunction in schizophrenia (Park and Holzman, 1992; Weickert et al, 2000; Weinberger et al, 1986, 2001; Wexler et al, 1998), and have been linked to evidence of diminished prefrontal dopamine signaling (Akil et al, 1999; Weinberger et al, 1988, 2001). Consistent with this notion, several [although not all (Semwal et al, 2001)] studies using the family-based transmission disequilibrium test have shown the high-activity Val allele of COMT, which presumably increases dopamine catabolism, to be preferentially transmitted to schizophrenic offspring (Egan et al, 2001; Kunugi et al, 1997; Li et al, 2000, 1996). Interestingly, this Val ${ }^{108 / 158}$ Met functional polymorphism has been reported to be associated with schizotypal personality traits even in healthy individuals, and in the same direction as observed in schizophrenic patients, that is, increased Val allele frequency (Avramopoulos et al, 2002). Given the pivotal role of prefrontal cortex in the pathogenesis of schizophrenia and the apparent relevance of COMT for prefrontal dopamine metabolism, we have investigated the expression of COMT mRNA in the prefrontal cortex in patients with schizophrenia compared to control subjects by in situ hybridization histochemistry. The relation of $\mathrm{Val} / \mathrm{Met}$ genotype upon COMT mRNA expression has also been assessed.

\section{MATERIALS AND METHODS}

\section{Brain Tissue Preparation}

Post-mortem human brains were collected at the Clinical Brain Disorders Branch (NIMH) as previously described (Kleinman et al, 1995). The collection of human brain specimens was approved by the Institutional Review Board of the NIMH Intramural Research Program. Cases were screened by police and/or by telephone interviews of family members for a history of medical and/or psychiatric problems, including alcohol abuse and illicit drug use. Any positive history of a psychiatric problem or excessive alcohol or drug use led to the exclusion of that case from the normal subjects group. In addition, $80 \%$ of all cases had toxicological screens of blood. If the medical examiner believed that the index of suspicion for illicit drugs or alcohol abuse was low, a toxicological screen was not performed. All brains (both normal subjects and patients with schizophrenia) were screened for signs of macroscopic pathology at the time of autopsy; brain sections were examined microscopically using Bielschowsky's silver stain on multiple cerebral areas to exclude the presence of neuritic pathology as seen in Alzheimer's disease. Those cases with an unclear psychiatric diagnosis, evidence of cocaine or PCP abuse (history and/or toxicology), cerebrovascular disease, autolysis, subdural hematoma, neuritic pathology, or other pathological features were excluded from the analysis.

Briefly, $1.0-1.5 \mathrm{~cm}$ coronal slabs through the hemisected cerebrum of each human brain were rapidly frozen in a prechilled dry ice-isopentane slurry bath and stored at $-80^{\circ} \mathrm{C}$. Cryostat sections ( $14 \mu \mathrm{m}$ thick) were prepared from dorsolateral prefrontal cortex (DLPFC) from 14 patients with a diagnosis of schizophrenia and 15 normal subjects.
Wherever possible, normal subjects were matched with those with schizophrenia with respect to gender, age at death, post-mortem interval (PMI), and $\mathrm{pH}$ of tissue (Table 1). The total dose of neuroleptic medication given to the patients was calculated by adding the various daily medication levels as determined from available medical records and converting these levels to chlorpromazine (CPZ) equivalents as previously formulated (Torrey, 1983).

\section{In Situ Hybridization}

T7/T3 promoter-tagged COMT riboprobe templates were generated by PCR as described (Matsumoto et al, 2003). The COMT riboprobe consisted of 321 bases, from the start codon of soluble COMT to just before the functional Val/ Met polymorphic site, which recognizes both the long $(1.5 \mathrm{~kb})$ and short $(1.3 \mathrm{~kb})$ COMT transcripts. Expression of COMT mRNA isoforms in the DLPFC of subjects in both diagnostic groups was determined by Northern blot analysis. Total RNA $(2 \mu \mathrm{g})$ extracted from DLPFC of five subjects from each diagnostic group (ID \#1, 3, 8, 11, 12 from normal control; ID \#1, 4, 7, 9, 14 from patients with schizophrenia) were pooled, electrophoresed, and transferred to a nylon membrane. The COMT riboprobe generation, hybridization, and signal detection for Northern analysis were performed as described (Matsumoto et al, 2003).

Fixation, acetylation, delipidation, and dehydration of the slices were performed according to standard protocols (Whitfield et al, 1990). ${ }^{35} \mathrm{~S}$-UTP labeled riboprobes for COMT with a specific activity of $1 \times 10^{9} \mathrm{cpm} / \mu \mathrm{g}$ were synthesized using T3 (for antisense) and T7 (for sense) RNA polymerase from the T7/T3 promoter tagged COMT riboprobe templates. Two sections from each subject were used (duplicate). A total volume of $200 \mu \mathrm{l}$ of hybridization buffer containing the ${ }^{35} \mathrm{~S}$-UTP labeled species-specific COMT riboprobes $(5 \mathrm{ng} / \mathrm{ml})$ were added to each section and hybridization was allowed to occur at $55^{\circ} \mathrm{C}$ overnight in humidified chambers. After hybridization, the slides were treated with RNase $\mathrm{A}$ and then washed under high stringency conditions $\left(0.2 \times \mathrm{SSC}, 55^{\circ} \mathrm{C}\right.$ for $1 \mathrm{~h}$ and $0.2 \times$ SSC, $60^{\circ} \mathrm{C}$ for $1 \mathrm{~h}$ ). After dehydration, hybridized slides, along with ${ }^{14} \mathrm{C}$ standards (American Radiolabeled Chemicals, Inc., St Louis, MO), were exposed to Kodak BioMax film for 1 week. The slides were dipped in an NT-B2 emulsion (Kodak), stored in light-tight boxes in the dark for 2 months and then developed in a D-19 developer (Kodak), dehydrated, and lightly stained with a Nissl counterstain. All the slides were processed together, so that direct quantitative comparisons could be made.

\section{Image Analysis}

Optical density measurements of the X-ray film were performed with the aid of NIH Image (Rasband, NIH). The boundary of Brodmann's area 46 (BA 46) was delineated on Nissl-stained sections, applying the criteria described by Rajkowska and Goldman-Rakic (1995). The cytoarchitectonic criteria used were as follows: (i) the presence of a well-defined granular layer IV; (ii) the columnar arrangement of pyramidal neurons in layer III; (iii) the increase in size of pyramidal neurons in layer III 
Table I Demographic data of patients with schizophrenia and normal subjects

\begin{tabular}{|c|c|c|c|c|c|c|c|c|c|c|c|}
\hline ID & Diagnosis & $\begin{array}{c}\text { COMT } \\
\text { genotype }\end{array}$ & Gender & Race & $\begin{array}{c}\text { Age at } \\
\text { death } \\
\text { (years) }\end{array}$ & $\begin{array}{l}\text { PMI } \\
\text { (h) }\end{array}$ & pH & $\begin{array}{l}\text { Cause of } \\
\text { death (manner) }\end{array}$ & $\begin{array}{c}\text { Last CPZ } \\
\text { equivalent } \\
\text { (mg/day) }\end{array}$ & $\begin{array}{c}\text { Daily CPZ } \\
\text { equivalent } \\
\text { (mg/day) }\end{array}$ & $\begin{array}{c}\text { Lifetime CPZ } \\
\text { equivalent } \\
\left(10^{6} \mathrm{mg}\right)\end{array}$ \\
\hline \multicolumn{12}{|c|}{ Patients and schizophrenia } \\
\hline 1 & CUS & W & M & AA & 75 & 42.5 & 6.29 & Undetermined & 400 & 400 & 5.3 \\
\hline 2 & CUS & W & $\mathrm{F}$ & AA & 67 & 38.5 & 6.63 & COPD & 80 & 100 & 1.3 \\
\hline 3 & CUS & MM & M & C & 31 & 14 & 6.46 & Undetermined & 200 & 250 & 0.4 \\
\hline 4 & CUS & VM & M & AA & 23 & 43 & 6.48 & Anoxia $2^{\circ}$ seizure disorder & 400 & 480 & 0.033 \\
\hline 5 & CPS & VM & $\mathrm{F}$ & AA & 60 & 35 & 6.38 & ASCVD & 100 & 100 & 0.7 \\
\hline 6 & CUS & VM & M & AA & 30 & 72.5 & 6.32 & Pneumonia cardiac hypertrophy & 1900 & 500 & 2.2 \\
\hline 7 & CUS & VM & M & AA & 35 & 79.5 & 6.7 & PE $2^{\circ}$ DVT (suicide) & $N / A$ & $N / A$ & $N / A$ \\
\hline 8 & CPS & W & M & C & 80 & 13.5 & 6.05 & Gl bleed & 30 & 50 & 0.7 \\
\hline 9 & CUS & VM & $\mathrm{F}$ & C & 81 & 15 & 6.78 & ASCVD & 100 & 150 & 2.1 \\
\hline 10 & CUS & VM & $\mathrm{F}$ & AA & 61 & 21.5 & 6.74 & Aspiration of food (accident) & $N / A$ & 200 & 2.0 \\
\hline 11 & CUS/TD & VM & M & AA & 38 & 61 & 6.5 & Acute peritonitis (accident) & 800 & 60 & 12 \\
\hline 12 & CUS & W & M & AA & 44 & 34 & 6.28 & Pulmonary abscess and empyema & 300 & 350 & 2.7 \\
\hline 13 & CDS & VM & $\mathrm{F}$ & AA & 41 & 51 & 6.08 & ASCVD & 2400 & 1135 & 10 \\
\hline \multirow[t]{2}{*}{14} & CUS & W & M & AA & 41 & 32 & 6.63 & ASCVD & 50 & 400 & 2.5 \\
\hline & Mean \pm SD & & & & $50.5 \pm 19.7$ & $39.5 \pm 20.9$ & $6.45 \pm 0.23$ & & & & \\
\hline
\end{tabular}

\begin{tabular}{|c|c|c|c|c|c|c|c|c|}
\hline ID & Diagnosis & $\begin{array}{c}\text { COMT } \\
\text { genotype }\end{array}$ & Gender & Race & $\begin{array}{l}\text { Age at } \\
\text { death } \\
\text { (years) }\end{array}$ & $\begin{array}{l}\text { PMl } \\
\text { (h) }\end{array}$ & $\mathrm{pH}$ & $\begin{array}{l}\text { Cause of } \\
\text { death (manner) }\end{array}$ \\
\hline \multicolumn{9}{|c|}{ Control subjects } \\
\hline I & CON & W & $\mathrm{F}$ & AA & 52 & 12 & 6.87 & Ruptured aorta \\
\hline 2 & CON & W & M & AA & 35 & 49.5 & 5.88 & ASCVD \\
\hline 3 & CON & $V M$ & M & AA & 41 & 14.5 & 6.72 & Stab wound to chest (homicide) \\
\hline 4 & CON & $V M$ & $\mathrm{~F}$ & C & 66 & 37.5 & 6.37 & Ruptured aorta \\
\hline 5 & CON & W & M & AA & 32 & 15.5 & 6.77 & GSW to chest (homicide) \\
\hline 6 & CON & W & M & AA & 24 & 12.5 & 6.59 & Pericarditis \\
\hline 7 & CON & W & M & AA & 38 & 32.5 & 6.14 & PE (accident) \\
\hline 8 & CON & W & M & AA & 18 & 14.5 & 6.51 & GSW to back (homicide) \\
\hline 9 & $\mathrm{CON}$ & W & M & AA & 83 & 66.5 & 6.01 & PE $2^{\circ} \mathrm{DVT}$ (accident) \\
\hline 10 & CON & VM & M & AA & 56 & 34 & 6.09 & $\mathrm{PE} 2^{\circ} \mathrm{DVT}$ \\
\hline 11 & CON & $V M$ & M & C & 63 & 19.5 & 6.54 & ASCVD with myocardial fibrosis \\
\hline 12 & CON & $\mathrm{VM}$ & $\mathrm{F}$ & AA & 52 & 26 & 6.38 & Pericarditis with tamponade \\
\hline 13 & CON & $V M$ & $\mathrm{~F}$ & AA & 57 & 19 & 6.43 & ASCVD \\
\hline 14 & CON & $V M$ & $\mathrm{~F}$ & AA & 59 & 37 & 6.57 & Cirrhosis of the liver \\
\hline 15 & $\mathrm{CON}$ & W & $\mathrm{F}$ & AA & $\begin{array}{c}67 \\
49.5+17.8\end{array}$ & $\begin{array}{c}34 \\
283+155\end{array}$ & $\begin{array}{c}6.69 \\
6.43+029\end{array}$ & Dilated cardiomyopathy \\
\hline \multicolumn{9}{|c|}{ Mean $\pm S D$} \\
\hline & $\begin{array}{l}\text { andard dev } \\
\text { Dups. Abbre } \\
M=\text { Met/M } \\
D=\text { chron } \\
\text { eath was na }\end{array}$ & $\begin{array}{l}\text { s are display } \\
\text { ns are as fo } \\
1=\text { Val/Met } \\
\text { tructive pulr } \\
\text { Chlorprom }\end{array}$ & $\begin{array}{l}\text { ed below } \\
\text { ows: COI } \\
\mathrm{V}=\mathrm{Val} / \\
\text { onary dise } \\
\text { zine equiv }\end{array}$ & $\begin{array}{l}\text { indivic } \\
\text { mal co } \\
\text { femal } \\
\mathrm{VT}=\mathrm{c} \\
\text { re sho }\end{array}$ & $\begin{array}{l}\text { each group. } \\
C D S=\text { chror } \\
\text { male, } A A= \\
\text { ein thrombo } \\
\text { milligram ec }\end{array}$ & $\begin{array}{l}\text { Gender, race, } \\
\text { nic disorganizec } \\
\text { African Americ } \\
\text { sis, GSW = gun } \\
\text { quivalents. }\end{array}$ & $\begin{array}{l}\text { e mean age } \\
\text { chizophrenia, } \\
\text { lot wound, } P\end{array}$ & $\begin{array}{l}\text { at death }(P>0.7 \mathrm{I}) \text {, post-mortem interval }(P>0.28) \text {, and } \mathrm{pH}(P>0.39) \text { did not differ between the } \\
C P S=\text { chronic paranoid schizophrenia, } C U S=\text { chronic undifferentiated schizophrenia, } T D=\text { tardive } \\
\text { sian, } P M I=\text { post-mortem interval, } 2^{\circ}=\text { secondary to, } A S C V D=\text { atherosclerotic coronary vascular } \\
E=\text { pulmonary embolism, } C P Z=\text { chlorpromazine, } N / A=\text { not available. Unless otherwise specified, }\end{array}$ \\
\hline
\end{tabular}


with an increase in cortical depth; and (iv) the presence of a clear transition from layer VI into the white matter. Sampling was carried out in BA 46, where the cortical layers were aligned parallel to the pial surface and conducted blind to diagnosis. A rectangle (approximately $2.1 \mathrm{~mm}^{2}$ ) was placed along the middle frontal sulcus, and the optical density for COMT mRNA in the gray matter (layers II-VI) was obtained by taking the average of six such boxes from two tissue sections per subject. For the white matter regions, the optical density was obtained by taking the average of six circles (approximately $1.7 \mathrm{~mm}^{2}$ ) from two tissue sections per subject. Optical densities normalized for sampled area $(\mu \mathrm{Ci} / \mathrm{g})$ per region were averaged across slices per subject.

In order to determine if COMT mRNA varied according to neuronal type (large pyramidal neurons vs smaller, presumably nonpyramidal neurons) or according to anatomical layer, silver grain analysis of neurons from layers II to VI was conducted blind to diagnosis on a Zeiss Axiophot (Gottingen, Germany) microscope equipped with a video camera and a Bioquant image analysis system (BIOQUANT). We counted grains on large pyramidal neurons (large cell size, light Nissl stain, and triangular shape) and smaller neurons (small cell size, light Nissl, and round shape) separately from layers II, III, IV, V, and VI. Although cells with a small, darkly stained nucleus with little cytoplasmic stain, presumably glial cells, occasionally appeared to have a positive hybridization signal, typically the signal was indistinguishable from the background. Therefore, glial cells were not analyzed. Circles of $30 \mu \mathrm{m}$ diameter for large pyramidal cells and $15 \mu \mathrm{m}$ diameter for smaller cells were drawn and centered over every neuron under the bright field. The illumination was then switched to dark field and the silver grains overlying a neuron, within the boundaries of this circle, were counted with the aid of a grain-counting macroprogram written using Bioquant software. Background silver grain level was determined by averaging the number of grains in three $30 \mu \mathrm{m}$-diameter circles (for pyramidal neurons) and in three $15 \mu \mathrm{m}$-diameter circles (for smaller neurons) in the neuropil of layer I from each sample. A total of 20 large pyramidal and 20 smaller neurons within each layer for each case from one tissue section were sampled from contiguous fields within BA46. The average number of grains per cell (background subtracted) from 20 neurons for each layer for each case was used in the statistical analysis. Images of silver grains from these slides were captured using a video camera mounted on a microscope Axiophot (ZEISS, Gottingen, Germany).

\section{Genotyping of COMT Val ${ }^{108 / 158}$ Met Allele}

The COMT genotype was determined by restriction fragment length polymorphism analysis with subtle modifications to the earlier method (Lachman et al, 1996). A $109 \mathrm{bp}$ PCR product was generated from brain genomic DNA from each subject using the primers $5^{\prime}$-CTCATCACCATCGAGATCAA-3' (sense, position 1881-1900 according to the GenBank accession number Z26491) and 5'-CCAGGTCTGACAACGGGTCA-3' (antisense, 1970-1989). The PCR product was digested with restriction enzyme NlaIII. The digested PCR fragments were separated on an agarose gel and visualized by ethydium bromide staining. The Val allele was recognized by 86 and 23 bp fragments and the Met allele by 68,18 , and 23 bp fragments.

\section{Statistical Analysis}

Diagnostic group differences in demographic variables, age at death, PMI, and $\mathrm{pH}$ were tested with unpaired $t$-tests (Statistica, Statsoft). Pearson Product-Moment correlation coefficients were used to assess the relations between COMT mRNA levels and the demographic variables, while unpaired $t$-tests were used to determine if gender differences in COMT mRNA existed. Paired $t$-tests were used to compare COMT mRNA levels between the gray matter and white matter area (optical density) or between large pyramidal and smaller neurons (silver grain). Comparison of COMT mRNA optical densities between the diagnostic groups and between the COMT genotype-groups was accomplished using unpaired $t$-tests. Two-way ANOVAs were run to explore interactions between diagnosis and COMT genotype. In order to analyze for differences in the laminar expression of COMT mRNA per neuron based on either diagnosis or COMT genotype, two-way repeated measures ANOVAs were run with diagnosis and COMT genotype as between group factors and the cortical layer as a within-group factor (the number of silver grains was the dependent variable). To explore interactions between diagnosis and lamina, one-way repeated measures ANOVAs were run testing for differences in COMT mRNA levels across layers in each diagnostic group followed by least significant difference post hoc tests. Additionally, unpaired $t$-tests comparing COMT mRNA levels in schizophrenia vs control were run for each layer. A three-way repeated measures ANOVA was used to determine interaction across diagnosis, COMT genotype, and laminar expression.

\section{RESULTS}

\section{In Situ Hybridization Histochemistry}

The specificity of the human COMT riboprobe was determined previously (Matsumoto et al, 2003). Consistent with the previous data, the long isoform of COMT mRNA $(1.5 \mathrm{~kb})$ but not the short isoform $(1.3 \mathrm{~kb})$, was detected in the DLPFC of subjects in both diagnostic groups by Northern blot analysis (data not shown; Hong et al, 1998; Matsumoto et al, 2003; Tenhunen et al, 1994). Hybridization of human DLPFC tissue sections with the ${ }^{35}$ S-labeled COMT antisense riboprobe generated a fairly robust signal, whereas hybridization with the sense riboprobe showed no obvious background signal (Figure 1a). Representative $\mathrm{X}$-ray film autoradiograms and high-power bright field images of DLPFC from patients with schizophrenia and normal subjects are shown in Figure 1b. The mean optical density of the COMT hybridization signal on X-ray film was significantly higher in the gray matter than in the white matter area in both diagnostic groups (Figures $1 \mathrm{~b}$ and 2). Silver grains were more numerous overlying large lightly stained neurons than over the small non-neuronal glial profiles, where the signal was typically indistinguishable or was occasionally slightly higher than the background level in both groups (Figure 1b). We have, however, consistently 


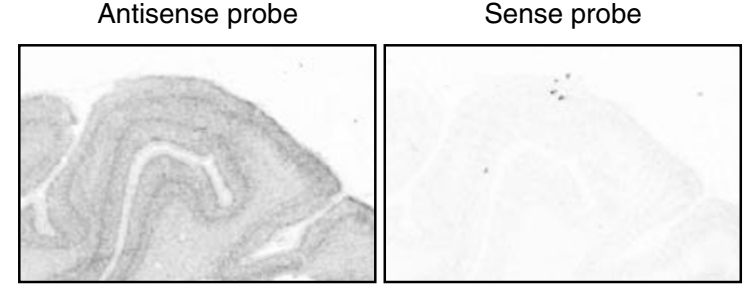

b

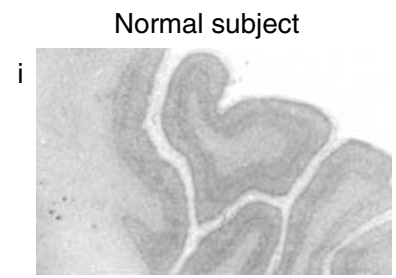

iii

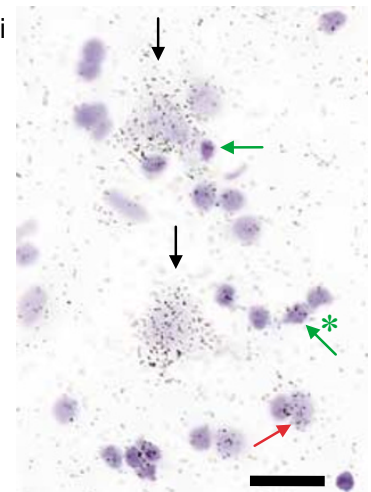

Patient with schizophrenia

iv

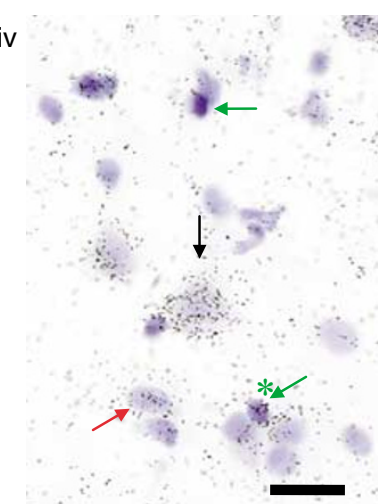

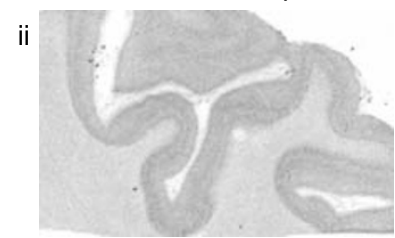

Figure I X-ray film autoradiogram images and high-power bright field images of in situ analysis of COMT mRNA in the DLPFC. (a) Representative $X$-ray film autoradiogram images from adjacent sections (normal subject) showing a robust signal with the antisense riboprobe, but no obvious background signal with the sense riboprobe. (b) Representative $X$-ray film autoradiogram images and photomicrographs (layer $V$, scale bar $=20 \mu \mathrm{m}$ ) from coronal DLPFC sections of normal subjects (i, iii) and patients with schizophrenia (ii, iv). Note that the large pyramidal neurons contain COMT silver grains at high densities (black arrows), while smaller-sized neurons contain relatively lower densities of silver grains (red arrows). Glial cells, identifiable by small darkly Nissl-stained nuclei, have silver grains at background levels (green arrows), but are occasionally slightly higher than background levels (green arrows with asterisk).

detected low levels of COMT mRNA signal in the white matter area (Figures 1 and 2), which implicates some glial expression of COMT mRNA, albeit at lower levels as compared to neurons. The number of silver grains was significantly greater on large pyramidal neurons as compared to smaller neurons (Figures 1 and 3).

\section{Comparison of COMT mRNA Levels between Diagnostic Groups}

Demographic variables, gender, mean age at death, PMI, and $\mathrm{pH}$ of tissue did not differ between the two groups of samples (Table 1). Furthermore, no relations were found between COMT mRNA levels in the gray matter of DLPFC and demographic variables; namely age at death $(r=-0.11$, $P=0.56)$, PMI $(r=-0.18, P=0.35), \mathrm{pH}$ of tissue $(r=0.24$, $P=0.21)$, and gender $(t=0.47, \mathrm{df}=27, \quad P=0.64)$. No correlations were detected between the COMT mRNA levels in patients with schizophrenia and neuroleptic medication
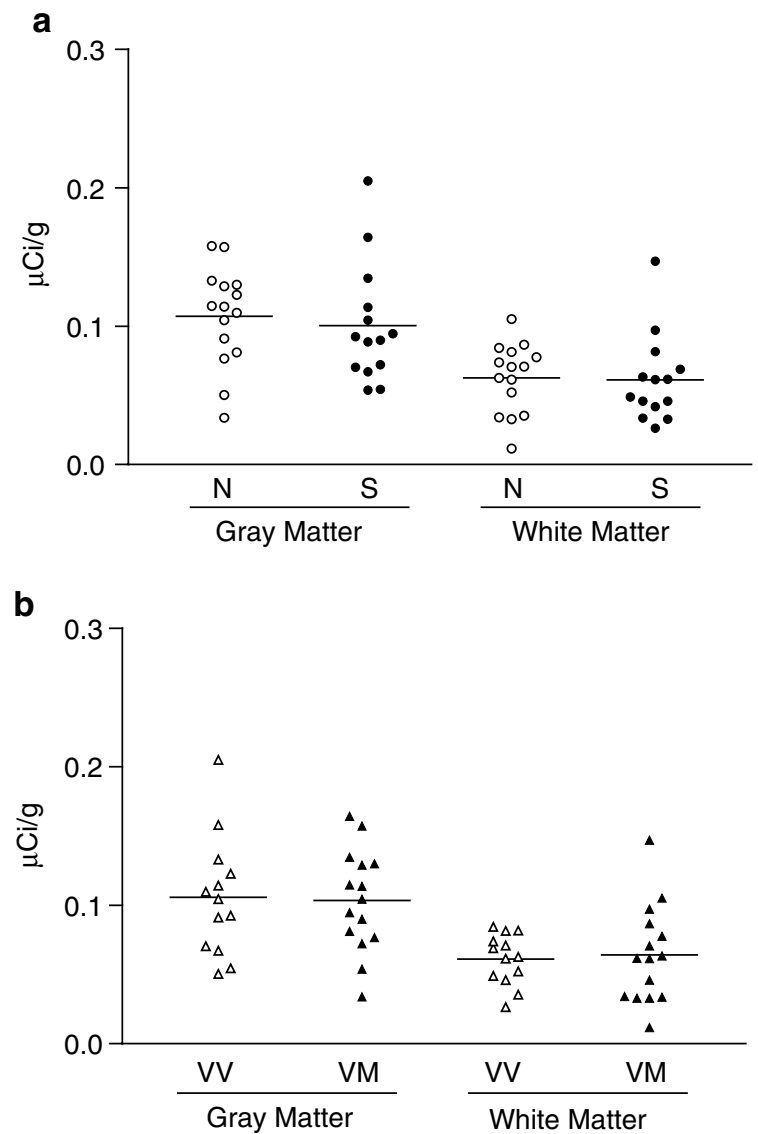

Figure 2 Comparison of COMT mRNA optical densities in the DLPFC on X-ray films (a) between diagnostic groups and (b) between COMT genotype-groups. (a) The mean COMT mRNA level in normal subjects (N) was $0.107 \pm 0.035 \mu \mathrm{Ci} / g$ (mean $\pm \mathrm{SD}$ ) in the gray matter and $0.063 \pm 0.025 \mu \mathrm{Ci} / \mathrm{g}$ in the white matter. The mean COMT mRNA level in patients with schizophrenia (S) was $0.100 \pm 0.043 \mu \mathrm{Ci} / \mathrm{g}$ (mean $\pm \mathrm{SD}$ ) in the gray matter and $0.061 \pm 0.031 \mu \mathrm{Ci} / g$ in the white matter. There was a significant difference in COMT mRNA levels between the gray and white matter in both groups of subjects (paired t-test, $P<0.000 \mathrm{I}$ ). (b) The mean COMT mRNA level in subjects who were homozygous for the Val allele (V) was $0.106 \pm 0.043 \mu \mathrm{Ci} / g$ (mean $\pm \mathrm{SD}$ ) in the gray matter and $0.061 \pm 0.018 \mu \mathrm{Ci} / g$ in the white matter. The mean COMT mRNA level in subjects who were heterozygous (VM) was $0.103 \pm 0.037 \mu \mathrm{Ci} / g$ (mean $\pm \mathrm{SD}$ ) in the gray matter and $0.064 \pm 0.035 \mu \mathrm{Ci} / \mathrm{g}$ in the white matter. There was a significant difference in COMT mRNA levels between the gray and white matter in both groups of subjects (paired $t$-test, $P<0.000$ I).

histories converted to $\mathrm{CPZ}$ equivalents (average daily doses $r=-0.26, P=0.40$, estimated lifetime doses $r=-0.24$, $P=0.43$, daily doses at death $r=-0.31, P=0.33$ ). When we analyzed COMT mRNA levels in the white matter area, again, no significant relation with demographic variables or neuroleptic medication was found (data not shown). Therefore, we did not utilize these demographic variables as covariates in further statistical analysis. Analysis of optical density on the X-ray films revealed no significant differences in mean levels of COMT mRNA between the groups of schizophrenic and normal subjects (gray matter, $t=0.46, \mathrm{df}=27, P=0.65$; white matter, $t=0.15, \mathrm{df}=27$, $P=0.88$; Figure $2 \mathrm{a}$ ).

Silver grain analysis of COMT mRNA in neurons (large pyramidal and smaller, presumably nonpyramidal neurons 

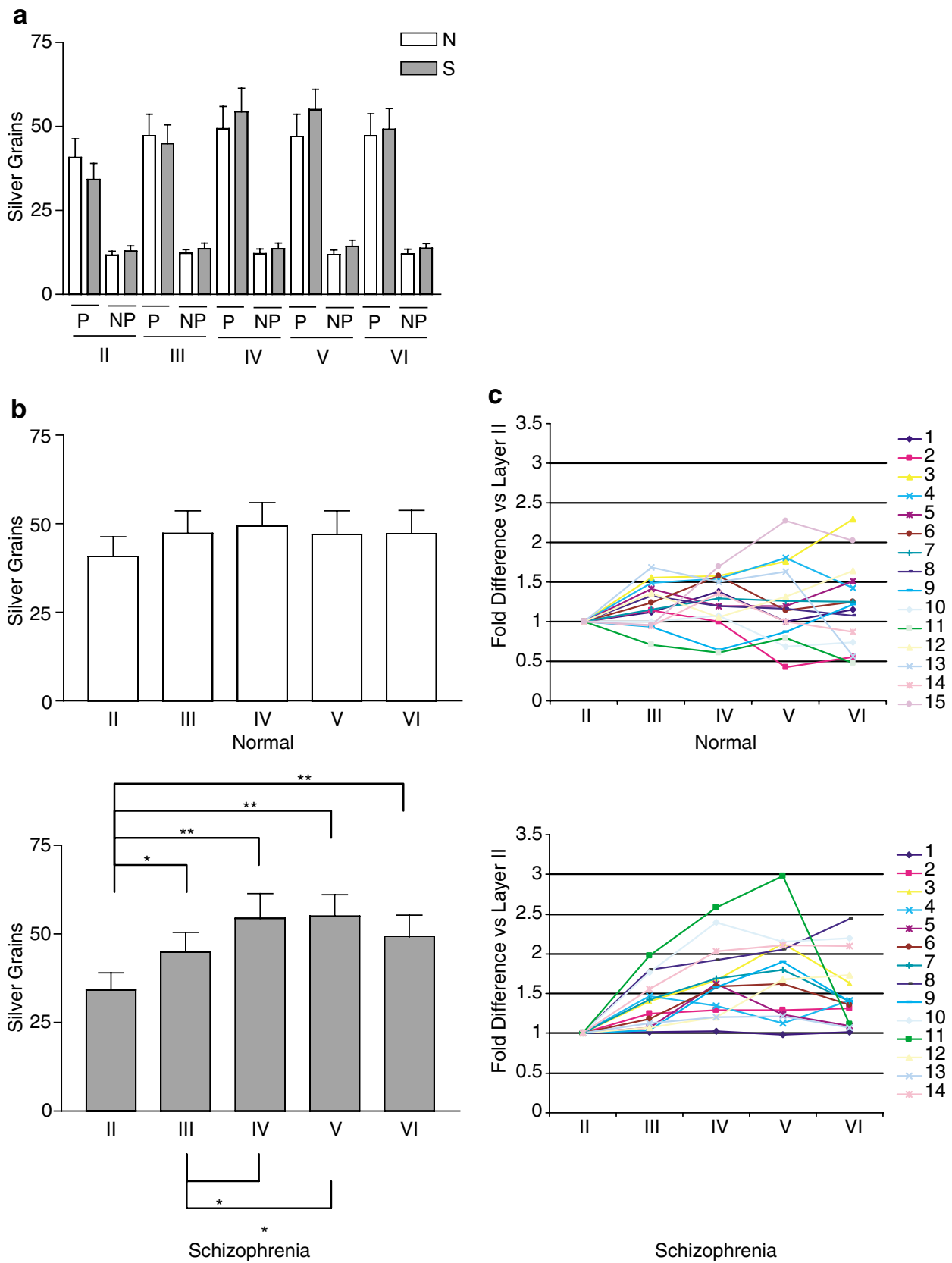

Figure 3 Comparison of silver grains on neurons in the DLPFC between diagnostic groups. (a) The mean number of silver grains in layers II-VI is shown on large pyramidal neurons (P) and on smaller, presumably nonpyramidal neurons (NP) in normal subjects (N) and in patients with schizophrenia (S). Error bars represent the standard error. There is a significant difference in the number of silver grains between the large and small neurons in both subject groups (paired t-test, $P<0.000 \mathrm{I}$ ). (b) The mean number of silver grains in layers $I I-\mathrm{VI}$ on large pyramidal neurons in normal subjects and in patients with schizophrenia. Error bars represent the standard error. Significant laminar differences are indicated by asterisks $(* P<0.01$; *** $<0.000 \mathrm{I})$. (c) The mean number of silver grains in layers II-VI on large pyramidal neurons in each individual was normalized by that of layer II (fold difference vs layer II).

from layers II to VI) using two-way repeated measures ANOVAs for each class of neuron confirmed the film analysis, revealing no main effect of diagnosis (large neurons, $\mathrm{F}=0.02, \mathrm{df}=1,27, \quad P=0.88$; small neurons, $\mathrm{F}=0.76, \mathrm{df}=1,27, \quad P=0.39 ;$ Figure $3 \mathrm{a})$. However, the analysis showed a significant effect of cortical layer $(\mathrm{F}=10.5, \mathrm{df}=4,108, P<0.0001)$ and a significant layer by diagnosis group interaction $(\mathrm{F}=2.68, \mathrm{df}=4,108, P<0.04)$ in large pyramidal neurons, but not in smaller neurons $(P=0.83$ and 0.90 , respectively). The laminar difference in COMT mRNA levels was still robust when the analysis was restricted to patients with schizophrenia $(P<0.0001)$, but no significant laminar effect was observed in normal subjects $(P=0.26)$. Post hoc comparison indicated that schizophrenic patients had lower levels of COMT mRNA in pyramidal neurons in the superficial layers (II/III) and higher levels in the intermediate/deep layers (IV/V) (Figure 3b). The laminar difference in the patient group was represented fairly consistently in each individual (Figure 3c). Levels of COMT mRNA in the individual layers did not differ between diagnostic groups when directly compared (all $P>0.38$ ). No relation was detected between 
the patients' medication histories and the COMT mRNA levels in any layer (large neurons, all $P>0.16$; small neurons, all $P>0.11$ ).

\section{Comparison of COMT mRNA Levels between the COMT Genotype-Groups}

In order to determine whether COMT genotype affects its own mRNA level, all subjects were genotyped at $\mathrm{Val}^{108 / 158}$ Met and divided into two groups: homozygous for the Val allele (Val/Val) and heterozygous (Val/Met). Since there was only one subject who was homozygous for the Met allele (Met/Met) in the present cohort, we did not include this subject in the statistical analysis. There was no difference between the two genotype-groups in the mean levels of optical density of COMT mRNA on X-ray film (gray matter, $t=0.15, \mathrm{df}=26, P=0.88$; white matter, $t=-0.28, \mathrm{df}=26$, $P=0.78$; Figure $2 \mathrm{~b})$. When the analysis was restricted to patients with schizophrenia or to normal subjects, again there were no differences between the two genotype-groups $(P>0.48)$. There were no interactions between diagnosis and COMT genotype $(P>0.40)$. Likewise, silver grain analysis of COMT mRNA in neurons showed no main effect of COMT genotype (large neurons, $\mathrm{F}=0.47, \mathrm{df}=1,26$, $P=0.50$; small neurons, $\mathrm{F}=0.15, \mathrm{df}=1,26, P=0.70)$. There was also no interaction between the cortical lamina and COMT genotype (large neurons, $P=0.35$; small neurons, $P=0.11$ ), or across cortical lamina and diagnosis and COMT genotype (large neurons, $P=0.79$; small neurons, $P=0.95)$.

\section{DISCUSSION}

We have examined the expression of COMT mRNA in brain tissue from patients with schizophrenia and from normal comparison subjects. COMT mRNA was detected at higher levels in large pyramidal neurons compared to smaller, presumably nonpyramidal neurons and was distributed from layers II to VI in the DLPFC. Although silver grains were occasionally detected in glial cells with dark Nisslstained nuclei (Figure 1), overall, the expression in these cells was typically indistinguishable from the background. The neuronal expression profile of COMT was also confirmed by the comparison between gray and white matter, which showed significantly higher levels of COMT mRNA in the gray matter. These results are similar to those reported previously (Matsumoto et al, 2003). Although the COMT riboprobe used in the present study recognizes both the long $(1.5 \mathrm{~kb})$ and short $(1.3 \mathrm{~kb})$ transcripts (Matsumoto et al, 2003), we and other groups have shown that the long COMT mRNA is the only isoform detectable in the human cortex (Hong et al, 1998; Matsumoto et al, 2003; Tenhunen et al, 1994). Consistent with this, Northern blot analysis detected only long COMT mRNA expression in the DLPFC of subjects in both diagnostic groups. Therefore, the mRNA signal detected in the present in situ study likely represents the long isoform of COMT transcript, which presumably leads to the predominant expression of the membrane bound type of COMT having a high affinity for catechol (Matsumoto et al, 2003; Tenhunen et al, 1994).
We have also assessed the effect of COMT Val ${ }^{108 / 158}$ Met genotype on its own mRNA level. The present comparison of individuals who are homozygous for the Val allele (Val/ $\mathrm{Val}$ ) and heterozygous (Val/Met) subjects has demonstrated no significant difference in the levels or laminar distribution of COMT mRNA, making it appear that a transcriptional mechanism aimed at compensating for the functional $\mathrm{Val}^{108 / 158}$ Met polymorphism does not occur. This is consistent with a recent finding by Yan et al (2002), showing no relation between COMT mRNA levels and the COMT genotype of $388 \mathrm{C} / \mathrm{T}$ SNP that is presumably in strong linkage disequilibrium with $\mathrm{Val} / \mathrm{Met}$ SNP due to their very small distance $(<500 \mathrm{bp})$. Our data are also consistent with experiments performed in Dr Paul Harisson's laboratory at Oxford University (personal communication). Previous studies have demonstrated that the Met allele COMT protein is thermolabile at body temperature and has less enzymatic activity in vivo (Lachman et al, 1996; Lotta et al, 1995). Together, these data suggest that the Val/Met substitution affects the net enzyme activity of COMT without any change in its mRNA levels in the DLPFC. The presumed direct effect of COMT Val ${ }^{108 / 158}$ Met on prefrontal dopamine metabolism is supported by previous data associating this functional polymorphism with observable dopamine-related prefrontal phenotypes, that is, working memory performance and prefrontal physiology (Bilder et al, 2002; Egan et al, 2001; Goldberg et al, in press; Joober et al, 2002; Malhotra et al, 2002; Rosa et al, 2002).

Although we did not find a difference in the mean levels of COMT mRNA in the DLPFC between patients with schizophrenia and normal subjects, we did detect a difference in laminar distribution. Pyramidal neurons of the patients expressed COMT mRNA at significantly lower levels in the superficial layers (II/III) and higher levels in the intermediate/deep layers (IV/V), while COMT mRNA expression in pyramidal neurons of normal subjects did not show such laminar variation. Importantly, we detected these laminar differences only in pyramidal neurons, and not in small, presumably nonpyramidal neurons. It is important to note that these findings reflected a difference in the laminar pattern of expression, as the mean expression in individual lamina did not differ between groups. In other words, while the absolute difference in COMT mRNA expression per pyramidal neuron was relatively small, the synaptic architecture of catecholamine synapses on pyramidal neurons may have undergone reorganization across cortical layers in schizophrenia. This is clearly a novel observation that will require independent replication.

We did not detect any correlation between the COMT mRNA levels and the medication histories of patients. Additionally, an earlier animal study has indicated that chronic neuroleptic treatment (ie haloperidol) does not affect brain COMT activity (Hannan, 1986). These data support the possibility that the disease-related laminar differences we have observed in the schizophrenic subjects reflect aspects of disease biology and are not epiphenomenona related to treatment.

The mechanism of this potential rearrangement of the molecular profile of prefrontal pyramidal neurons is a matter of speculation, but likely involves the synaptic organization of these neurons. Since COMT proteins have been detected exclusively in the neuropil of the cerebral 
cortex (Kaplan et al, 1979; Karhunen et al, 1994; Lundstrom et $a l, 1995)$ and neurons are the primary cell population producing COMT mRNA, it is reasonable to assume that COMT is located at dendrites and/or spines in the prefrontal cortex (Matsumoto et al, 2003). Interestingly, the prefrontal cortex of patients with schizophrenia has been reported to show reduced cortical neuropil, particularly in layer II (Selemon et al, 1998), and decreased somal size of pyramidal neurons in layer III (Pierri et al, 2001; Rajkowska et al, 1998), both of which could be related to reduced dendritic arborization. Thus, lower levels of pyramidal COMT mRNA in these external cortical layers may reflect this putative reduction of dendrites and/or spines, where COMT protein is presumably located, and may implicate catecholaminergic synapses as part of this process. In fact, studies in animals indicate that the activity of dopamine inputs to the prefrontal cortex directly covary with the density of spines (Robinson and Kolb, 1999).

Previous anatomical studies in monkey (Goldman-Rakic et al, 1989; Krimer et al, 1997; Lewis, 1992; Smiley and Goldman-Rakic, 1993) and human (Akil et al, 1999; Lewis, 1992) brain have demonstrated that dopaminergic projections to DLPFC are highly organized and distributed in a bilaminar manner at high densities in the superficial (I/II) and deep layers (V/VI), whereas the distribution is more uniform in the dorsomedial region of this cortical area. The majority of dopaminergic terminals synapse on pyramidal neurons, while dopaminergic contacts on nonpyramidal neurons are much less dense and are irregularly distributed (Goldman-Rakic et al, 1989; Krimer et al, 1997; Smiley and Goldman-Rakic, 1993). Consistent with this, our present data show higher levels of COMT mRNA in pyramidal than in small, presumably nonpyramidal neurons. Electrochemical studies in the monkey brain have demonstrated that dopamine inputs modulate cortical neuronal excitability in a complex manner, with the potentiation of pyramidal postsynaptic currents (Henze et al, 2000) and also with inhibition via a presynaptic mechanism (Gao et al, 2001). Moreover, these pyramidal neurons are connected horizontally and vertically by intrinsic collaterals in the prefrontal cortex (Levitt et al, 1993). The laminar imbalance of COMT expression, which presumably leads to imbalance of dopamine availability at the synaptic level, may contribute to dysregulation of pyramidal neuronal circuitry in the prefrontal cortex, albeit to a relatively small degree. In an earlier immunohistochemical study of dopamine terminals in the dorsomedial prefrontal cortex, patients with schizophrenia displayed significantly reduced dopaminergic innervation in the deeper layers (Akil et al, 1999). The reduction of dopaminergic input in deep layers has also been observed in the dorsolateral region (Akil $\mathrm{M}$, personal communication). Importantly, this alternation in patients with schizophrenia is opposite to that of COMT mRNA expression in pyramidal cells, especially in layer $\mathrm{V}$, where decreased dopamine innervation and relatively higher levels of COMT mRNA have been detected. Given that prefrontal pyramidal neurons in layer $\mathrm{V}$ project to the striatum and brainstem and appear to tonically inhibit striatal dopamine synthesis/release (Carlson et al, 1991; Carr and Sesack, 2000; Ferry et al, 2000; Kolachana et al, 1995; Pycock et al, 1980; Saunders et al, 1998), it is tempting to speculate that these various disease-related changes in layer $\mathrm{V}$, that is, diminished dopamine innervation and increased COMT expression, synergistically contribute to a relative hypodopaminergic state at the level of prefrontal neuronal signaling and a hyperdopaminergic state at the level of striatal function, which has been implicated in the pathophysiology of schizophrenia (Bertolino et al, 2000; Grace, 2000; Laruelle et al, 1996; Meyer-Lindenberg et al, 2002; Weinberger, 1987; Weinberger et al, 1988). Finally, the combined effects of this laminar imbalance of dopamine innervation and COMT expression might explain, at least partly, recent evidence that the COMT Val ${ }^{108 / 158}$ Met polymorphism has a greater impact upon working memory performance in patients with schizophrenia than in normal subjects (Joober et al, 2002).

In conclusion, our present data show that the functional impact of the COMT $\mathrm{Val}^{108 / 158}$ Met polymorphism on DLPFC is not compensated by a genotype-associated change in its own mRNA expression. The disease-dependent laminar differences in COMT mRNA expression provide additional evidence of an abnormality of dopamine neurotransmission in the DLPFC of patients with schizophrenia.

\section{ACKNOWLEDGEMENTS}

We acknowledge Dr Mayada Akil for her helpful discussion and Matthew R Livingood for technical assistance. We are deeply indebted to the families of individuals included in this study.

\section{REFERENCES}

Akil M, Pierri JN, Whitehead RE, Edgar CL, Mohila C, Sampson AR et al (1999). Lamina-specific alterations in the dopamine innervation of the prefrontal cortex in schizophrenic subjects. Am J Psychiatry 156: 1580-1589.

Avramopoulos D, Stefanis NC, Hantoumi I, Smyrnis N, Evdokimidis I, Stefanis CN (2002). Higher scores of self reported schizotypy in healthy young males carrying the COMT high activity allele. Mol Psychiatry 7: 706-711.

Bertolino A, Breier A, Callicott JH, Adler C, Mattay VS, Shapiro M et al (2000). The relationship between dorsolateral prefrontal neuronal $\mathrm{N}$-acetylaspartate and evoked release of striatal dopamine in schizophrenia. Neuropsychopharmacology 22: 125-132.

Bilder RM, Volavka J, Czobor P, Malhotra AK, Kennedy JL, Ni X et al (2002). Neurocognitive correlates of the COMT Val(158)Met polymorphism in chronic schizophrenia. Biol Psychiatry 52: 701-707.

Carlson JN, Fitzgerald LW, Keller Jr RW, Glick SD (1991). Side and region dependent changes in dopamine activation with various durations of restraint stress. Brain Res 550: 313-318.

Carr DB, Sesack SR (2000). Projections from the rat prefrontal cortex to the ventral tegmental area: target specificity in the synaptic associations with mesoaccumbens and mesocortical neurons. J Neurosci 20: 3864-3873.

Egan MF, Goldberg TE, Kolachana BS, Callicott JH, Mazzanti CM, Straub RE et al (2001). Effect of COMT Val108/158 Met genotype on frontal lobe function and risk for schizophrenia. Proc Natl Acad Sci USA 98: 6917-6922.

Ferry AT, Ongur D, An X, Price JL (2000). Prefrontal cortical projections to the striatum in macaque monkeys: evidence for an organization related to prefrontal networks. J Comp Neurol 425 : 447-470. 
Gao WJ, Krimer LS, Goldman-Rakic PS (2001). Presynaptic regulation of recurrent excitation by $\mathrm{D} 1$ receptors in prefrontal circuits. Proc Natl Acad Sci USA 98: 295-300.

Garris PA, Collins LB, Jones SR, Wightman RM (1993). Evoked extracellular dopamine in vivo in the medial prefrontal cortex. $J$ Neurochem 61: 637-647.

Giros B, Jaber M, Jones SR, Wightman RM, Caron MG (1996). Hyperlocomotion and indifference to cocaine and amphetamine in mice lacking the dopamine transporter. Nature 379: 606-612.

Gogos JA, Morgan M, Luine V, Santha M, Ogawa S, Pfaff D et al (1998). Catechol-O-methyltransferase-deficient mice exhibit sexually dimorphic changes in catecholamine levels and behavior. Proc Natl Acad Sci USA 95: 9991-9996.

Goldberg TE, Egan MF, Gscheidle T, Coppola R, Weickert TW, Kolachana BS et al (in press). Executive subprocesses in working memory: relationships with COMT Val108/158Met genotype and genetic risk for schizophrenia. Arch Gen Psychiatry.

Goldman-Rakic PS, Leranth C, Williams SM, Mons N, Geffard M (1989). Dopamine synaptic complex with pyramidal neurons in primate cerebral cortex. Proc Natl Acad Sci USA 86: $9015-9019$.

Grace AA (2000). Gating of information flow within the limbic system and the pathophysiology of schizophrenia. Brain Res Brain Res Rev 31: 330-341.

Hannan Jr CJ (1986). Beta-phenylethylamine effect on brain and blood catechol-O-methyltransferase activity. Pharmacol Biochem Behav 24: 1141-1146.

Henze DA, Gonzalez-Burgos GR, Urban NN, Lewis DA, Barrionuevo G (2000). Dopamine increases excitability of pyramidal neurons in primate prefrontal cortex. J Neurophysiol 84: 2799-2809.

Hong J, Shu-Leong H, Tao X, Lap-Ping Y (1998). Distribution of catechol-O-methyltransferase expression in human central nervous system. Neuroreport 9: 2861-2864.

Huotari M, Gogos JA, Karayiorgou M, Koponen O, Forsberg M, Raasmaja A et al (2002). Brain catecholamine metabolism in catechol-O-methyltransferase (COMT)-deficient mice. Eur J Neurosci 15: 246-256.

Joober R, Gauthier J, Lal S, Bloom D, Lalonde P, Rouleau G et al (2002). Catechol-O-methyltransferase Val-108/158-Met gene variants associated with performance on the Wisconsin Card Sorting Test. Arch Gen Psychiatry 59: 662-663.

Kaplan GP, Hartman BK, Creveling CR (1979). Immunohistochemical demonstration of catechol-O-methyltransferase in mammalian brain. Brain Res 167: 241-250.

Karhunen T, Tilgmann C, Ulmanen I, Julkunen I, Panula P (1994). Distribution of catechol-O-methyltransferase enzyme in rat tissues. J Histochem Cytochem 42: 1079-1090.

Karoum F, Chrapusta SJ, Egan MF (1994). 3-Methoxytyramine is the major metabolite of released dopamine in the rat frontal cortex: reassessment of the effects of antipsychotics on the dynamics of dopamine release and metabolism in the frontal cortex, nucleus accumbens, and striatum by a simple two pool model. J Neurochem 63: 972-979.

Kleinman JE, Hyde TM, Herman MM (1995). Methodological issues in the neuropathology of mental illness. In: Bloom FE, Kupfer DI (eds) Psychopharmacology: The Fourth Generation of Progress. Raven Press: New York. pp 859-864.

Kolachana BS, Saunders RC, Weinberger DR (1995). Augmentation of prefrontal cortical monoaminergic activity inhibits dopamine release in the caudate nucleus: an in vivo neurochemical assessment in the rhesus monkey. Neuroscience 69: 859-868.

Krimer LS, Jakab RL, Goldman-Rakic PS (1997). Quantitative three-dimensional analysis of the catecholaminergic innervation of identified neurons in the macaque prefrontal cortex. $J$ Neurosci 17: 7450-7461.

Kunugi H, Vallada HP, Sham PC, Hoda F, Arranz MJ, Li T et al (1997). Catechol-O-methyltransferase polymorphisms and schi- zophrenia: a transmission disequilibrium study in multiply affected families. Psychiatr Genet 7: 97-101.

Lachman HM, Papolos DF, Saito T, Yu YM, Szumlanski CL, Weinshilboum RM (1996). Human catechol-O-methyltransferase pharmacogenetics: description of a functional polymorphism and its potential application to neuropsychiatric disorders. Pharmacogenetics 6: 243-250.

Laruelle M, Abi-Dargham A, van Dyck CH, Gil R, D’Souza CD, Erdos J et al (1996). Single photon emission computerized tomography imaging of amphetamine-induced dopamine release in drug-free schizophrenic subjects. Proc Natl Acad Sci USA 93: 9235-9240.

Levitt JB, Lewis DA, Yoshioka T, Lund JS (1993). Topography of pyramidal neuron intrinsic connections in macaque monkey prefrontal cortex (areas 9 and 46). J Comp Neurol 338: 360-376.

Lewis DA (1992). The catecholaminergic innervation of primate prefrontal cortex. J Neural Transm 36(Suppl): 179-200.

Lewis DA, Melchitzky DS, Sesack SR, Whitehead RE, Auh S, Sampson A (2001). Dopamine transporter immunoreactivity in monkey cerebral cortex: regional, laminar, and ultrastructural localization. J Comp Neurol 432: 119-136.

Li T, Ball D, Zhao J, Murray RM, Liu X, Sham PC et al (2000). Family-based linkage disequilibrium mapping using SNP marker haplotypes: application to a potential locus for schizophrenia at chromosome 22q11. Mol Psychiatry 5: 77-84.

Li T, Sham PC, Vallada H, Xie T, Tang X, Murray RM et al (1996). Preferential transmission of the high activity allele of COMT in schizophrenia. Psychiatr Genet 6: 131-133.

Lotta T, Vidgren J, Tilgmann C, Ulmanen I, Melen K, Julkunen I et al (1995). Kinetics of human soluble and membrane-bound catechol $O$-methyltransferase: a revised mechanism and description of the thermolabile variant of the enzyme. Biochemistry 34: 4202-4210.

Lundstrom K, Tenhunen J, Tilgmann C, Karhunen T, Panula P, Ulmanen I (1995). Cloning, expression and structure of catecholO-methyltransferase. Biochim Biophys Acta 1251: 1-10.

Malhotra AK, Kestler LJ, Mazzanti C, Bates JA, Goldberg T, Goldman D (2002). A functional polymorphism in the COMT gene and performance on a test of prefrontal cognition. Am J Psychiatry 159: 652-654.

Mannisto PT, Kaakkola S (1999). Catechol-O-methyltransferase (COMT): biochemistry, molecular biology, pharmacology, and clinical efficacy of the new selective COMT inhibitors. Pharmacol Rev 51: 593-628.

Matsumoto M, Shannon Weickert C, Akil M, Lipska BK, Hyde TM, Herman MM et al (2003). Catechol $O$-methyltransferase mRNA expression in human and rat brain: evidence for a role in cortical neuronal function. Neuroscience 116: 127-137.

Mattay VS, Goldberg TE, Fera F, Hariri AR, Tessitore A, Egan MF et al (2003). COMT val158met genotype and individual variation in the brain response to amphetamine. Proc Natl Acad Sci USA 100: 6186-6191.

Mazei MS, Pluto CP, Kirkbride B, Pehek EA (2002). Effects of catecholamine uptake blockers in the caudate-putamen and subregions of the medial prefrontal cortex of the rat. Brain Res 936: 58-67.

Meyer-Lindenberg A, Miletich RS, Kohn PD, Esposito G, Carson RE, Quarantelli $M$ et al (2002). Reduced prefrontal activity predicts exaggerated striatal dopaminergic function in schizophrenia. Nat Neurosci 5: 267-271.

Park S, Holzman PS (1992). Schizophrenics show spatial working memory deficits. Arch Gen Psychiatry 49: 975-982.

Pierri JN, Volk CL, Auh S, Sampson A, Lewis DA (2001). Decreased somal size of deep layer 3 pyramidal neurons in the prefrontal cortex of subjects with schizophrenia. Arch Gen Psychiatry 58: 466-473.

Pycock CJ, Carter CJ, Kerwin RW (1980). Effect of 6-hydroxydopamine lesions of the medial prefrontal cortex on 
neurotransmitter systems in subcortical sites in the rat. $J$ Neurochem 34: 91-99.

Rajkowska G, Goldman-Rakic PS (1995). Cytoarchitectonic definition of prefrontal areas in the normal human cortex: I. Remapping of areas 9 and 46 using quantitative criteria. Cereb Cortex 5: 307-322.

Rajkowska G, Selemon LD, Goldman-Rakic PS (1998). Neuronal and glial somal size in the prefrontal cortex: a postmortem morphometric study of schizophrenia and Huntington disease. Arch Gen Psychiatry 55: 215-224.

Robinson TE, Kolb B (1999). Alterations in the morphology of dendrites and dendritic spines in the nucleus accumbens and prefrontal cortex following repeated treatment with amphetamine or cocaine. Eur J Neurosci 11: 1598-1604.

Rosa A, Zarzuela A, Cuesta M, Peralta V, Martinez-Larrea A, Serrano $\mathrm{F}$ et al (2002). New evidence for association between COMT gene and prefrontal neurocognitive functions in schizophrenia. Schizophr Res 53(Suppl): 69-70.

Saunders RC, Kolachana BS, Bachevalier J, Weinberger DR (1998). Neonatal lesions of the medial temporal lobe disrupt prefrontal cortical regulation of striatal dopamine. Nature 393: 169-171.

Selemon LD, Rajkowska G, Goldman-Rakic PS (1998). Elevated neuronal density in prefrontal area 46 in brains from schizophrenic patients: application of a three-dimensional, stereologic counting method. J Comp Neurol 392: 402-412.

Semwal P, Prasad S, Bhatia T, Deshpande SN, Wood J, Nimgaonkar VL et al (2001). Family-based association studies of monoaminergic gene polymorphisms among North Indians with schizophrenia. Mol Psychiatry 6: 220-224.

Sesack SR, Hawrylak VA, Matus C, Guido MA, Levey AI (1998). Dopamine axon varicosities in the prelimbic division of the rat prefrontal cortex exhibit sparse immunoreactivity for the dopamine transporter. J Neurosci 18: 2697-2708.

Smiley JF, Goldman-Rakic PS (1993). Silver-enhanced diaminobenzidine-sulfide (SEDS): a technique for high-resolution immunoelectron microscopy demonstrated with monoamine immunoreactivity in monkey cerebral cortex and caudate. $J$ Histochem Cytochem 41: 1393-1404.
Tenhunen J, Salminen M, Lundstrom K, Kiviluoto T, Savolainen R, Ulmanen I (1994). Genomic organization of the human catechol $O$-methyltransferase gene and its expression from two distinct promoters. Eur J Biochem 223: 1049-1059.

Torrey EF (1983). Surviving Schizophrenia. Harper, Row: New York.

Wayment HK, Schenk JO, Sorg BA (2001). Characterization of extracellular dopamine clearance in the medial prefrontal cortex: role of monoamine uptake and monoamine oxidase inhibition. $J$ Neurosci 21: 35-44.

Weickert TW, Goldberg TE, Gold JM, Bigelow LB, Egan MF, Weinberger DR (2000). Cognitive impairments in patients with schizophrenia displaying preserved and compromised intellect. Arch Gen Psychiatry 57: 907-913.

Weinberger DR (1987). Implications of normal brain development for the pathogenesis of schizophrenia. Arch Gen Psychiatry 44: 660-669.

Weinberger DR, Berman KF, Chase TN (1988). Mesocortical dopaminergic function and human cognition. Ann NY Acad Sci 537: 330-338.

Weinberger DR, Berman KF, Zec RF (1986). Physiologic dysfunction of dorsolateral prefrontal cortex in schizophrenia. I. Regional cerebral blood flow evidence. Arch Gen Psychiatry 43: 114-124.

Weinberger DR, Egan MF, Bertolino A, Callicott JH, Mattay VS, Lipska BK et al (2001). Prefrontal neurons and the genetics of schizophrenia. Biol Psychiatry 50: 825-844.

Wexler BE, Stevens AA, Bowers AA, Sernyak MJ, Goldman-Rakic PS (1998). Word and tone working memory deficits in schizophrenia. Arch Gen Psychiatry 55: 1093-1096.

Whitfield Jr HJ, Brady LS, Smith MA, Mamalaki E, Fox RJ, Herkenham M (1990). Optimization of cRNA probe in situ hybridization methodology for localization of glucocorticoid receptor mRNA in rat brain: a detailed protocol. Cell Mol Neurobiol 10: 145-157.

Yan H, Yuan W, Velculescu VE, Vogelstein B, Kinzler KW (2002). Allelic variation in human gene expression. Science 297: 1143. 